\title{
Ojigi: The Ethics of Japanese Community's Nonverbal Language
}

\author{
Miftachul Amri \\ Universitas Negeri Surabaya \\ Surabaya, Indonesia \\ miftachulamri@unesa.ac.id
}

\begin{abstract}
This paper discusses about Ojigi: the ethics of Japanese community nonverbal language. Bowing (Ojigi) is the ethics to greet each other Japanese culture which is part of nonverbal communication by respecting the other person during the interaction. The interaction can be mean directly facing the interlucotor or vise versa, such as during phone call. Ojigi almost always done everyday by kids to adults. Therefore, learning Ojigi is a must for Japanese language learners. In other words, this ethic has popularized in almost all of Japanese community. Even forigners who are learning Japanese will not be separated from Ojigi when interacting with others. The methodology used to achieve the target was trough data collection by document study. The specific target in this study is cultivating Ojigi as a target language culture for Japanese language learners. Ojigi has life's values since a long time ago which is believes by Japanese as one of the effective nonverbal communication. The result of this study is obtained information about the values contained in Ojigi and that is the Ojigi's secret which was explored in depth in this research. Ojigi consists of several types namely simple Ojigi (Eshaku), common Ojigi (Futsuu no Ojigi), and the Ojigi's innermost actions (Saikeirei). In Japan, there are two kind of Ojigi commonly found in Japanese daily life, namely Eshaku and Futsuu no Ojigi which use levels of bow depth as a rule.
\end{abstract}

Keywords—ojigi; eshaku; saikeirei; nonverbal language

\section{INTRODUCTION}

Japanese nonverbal communiation, Ojigi ( bowing the body during the interaction), seems still lack of serious attention from Japanese language larners. This is proven by less numbers of research about Ojigi. Whereas Ojigi is the foundation of Japanese politeness. Its function, sometimes, can replace verbal communiation. Amri [1] stated that if Japanese expressed their gratitude trough action, there will not be any other things to do except Ojigi. Japanese will bow to show gratitude. This is meant by politeness foundation of Japanese. In other words, the act of bowing head is called Ojigi.

Ojigi means Greetings by bowing head. Of course the definition of bowing head above is not parallel with the our way to bow. The importance of Ojigi in Japanese non-verbal communication clearly illustrated in the Japanese Language Education Guidebook (Nihongo Kyooiku Handobukku) by Sugito [2], as follows:

The education of nonverbal communication nowadays almost never conducted structurally, such as Ojigi in greetings. In Japan, Ojigi is very important. Ojigi is a typical culture of Japanese. It is Japanese national identity which is impplemented massively, solemnly, meaningful, purposively, amd valueable. Therefore it is very important for Japanese language learners to understand Ojigi and know how to implement it appropriately.

The research problem of the study is to find out the functions of Ojigi, the types of Ojigi and the verbal sentences that accompany Ojigi as well as the reasons why Japanese people do Ojigi.

\section{A. The nature of Ojigi}

Ojigi is Japanese nonverbal language to communicate each other. It is Japanese national identity. The word Ojigi etymologycally came from the word jigi which means a good hope while doing someting. Ojigi in Kokugo Jiten [3] means bowing head and giving salutation. Fukuda [4] explains that Ojigi is (1) greeting and bowing head; (2) rejection. In another dictionary, Daijisen [5] mentioned that Ojigi is (1) salutation by bowing head; (2) greeting by bowing head; (3) rejection, resignation, (4) reluctantm (5) greeting. While in Kojien [6] explained that Ojigi is (1) salutation (keirei) by bowing head, (2) objection, resignation; (2) reluctant.

Based on those definitons, it can be concluded that Ojigi is salutation by bowing head. Bowing head in Ojigi is an expression to obey or reject. In other words, ojigu means expression to respect eash other and remove the adversary wall.

This culture has been practiced by Japanese since Yayoi (10th century BC). In a text mentioned that people at that era unite two hand when wishing to Gods. This phenomenon still can be seen when Japanese pray in the tamples. Before praying, they will clap their hand and bow. In faily life nowadays, they no longer clap their hands because each person carries an innate in their hands. Therefore, it is simplified by only bowing or bowing head.

Ojigi has been a tradition passed trough generation since Japanese were a kid. They get used to bow to show respect, apology, and pray. The movement sometimes practices repeatedly with different tilt.

\section{METHODS}

This type of research is included in a qualitative descriptive study by conducting library research and interviews with Japanese people in Surabaya as informants. 


\section{RESUlTS AND DISCUSSION}

\section{A. Kinds of Ojigi}

\section{1. $\quad$ Ritsurei and Zarei}

There are two kind of Ojigi, those are Ritsurei and Zarei. Ojigi which is done by standing up called Ritsurei, while it is done by sitting called zarei. The rules of Ojigi are also varies based on gender. For males, ritsurei is practiced by bowing and press hips and buttat the same time to maintain balence. While for females, ritsurei is practiced by bowing and putting two hands with all fingers close in front of the body.

\section{Based on the intensity of bowing}

Amri [7] rejects Ogoshi [8] statement which mentioned that there are many words fro Ojigi, such as kootoo, rei, keirei, saikeirei, eshaku, ichirei, toori, mokurei, chinrei, and so on. According to Kanemoto, kootoo, rei, keirei, saikeirei, eshaku, ichirei, toori, mokurei, and chinrei are not part of Ojigi. Another opinion stated by Horiuchi [9], that in fact there are three kins of Ojigi, namely Eshaku (simple bow), Ojigi (common bow), dan Teinei na Ojigi (polite bow). While Amri [7] devided it into Eshaku (simple bow), Ojigi (respect bow), dan Fukai Ojigi (deep bow). In line with Horiuchi, Fukuda [4] said that it is normal that Ojigi has many levels because Ojigi is practiced in different situation. He argued that basically ojigi has three categories which are distinguished from the bending angle. Eshaku (little bow, bowing head), Keirei (total bow), dan Saikeirei (bow very deep to worship).

However, those statemnet do not in line with Rahmat [10], because according to him saikeirei and keirei are not Ojigi because they are only used in military and the differences are shown by different kanji characters in saikeirei and ojigi. Ojigi means bowing, while saikeirei means respecting deeply.

The difference of Ojigi terms dividen into bowing intencity which can be assumed by different degree.

a. Nodding quitely, five degrees

It is a little nod which is done when meeting neighbors or old friends, or it is also used by the supervisors to their employees.

b. Bowing to greet (Eshaku), fifteen degrees

This one is formal Ojigi which is done while meeting unintimate colleagus or acquitances

c. Bowing to give respect (Keirei), thirty degrees

An Ojigi which is given to the superiors or elders.

d. Bowing to give highest level of respect (Saikeirei), fourty five degrees.

It has a meaningful significance. It is usually done to apologize after making a big mistake. It also given while meeting people in high position such as the emperor.

e. Bend on knees

It means deeper than saikeirei. It is done if someone make a fatal mistake such as endanger other people's life. This was also an old way to respect Japanese emperor in the past.

However, Ojigi which are commonly known are Eshaku, Futsuu no Ojigi, dan Teinei na Ojigi. Eshaku in this context even explained as fifteen degrees bowing and done when meet acquitances or friends. More common Ojigi, like employees greet their customers, greet acquintances in the streets, or replay employees' bows by the superiors. It is normally used by any level of commuities as a daily greeting.

Moreover, there is Futsuu no Ojigi. It is another form of bows which is usually given to the oponent in formal ceremonies or deep apologizes. Futsuu no Ojigi has thirty degrees of angle. According to Nomura [11], it is difficult to do precisely thirty degrees and because there is no pressure in doing Ojigi. It is just a simple bowing the head or it could be bending the body twice or three times while standing out and exhaling hardly

The last is Teinei na Ojigi. It is the most polite and respectful Ojigi. It has fourty five degrees acute angle or more. It is usually practiced while apologizing or meeting important people and in other formal situations. Besides, it is also used while praying in the tamples because this kind of Ojigi previously only given to the Gods or Emperors Fukuda [4].

\section{B. Procedures in performing Ojigi}

As what has been stated by Ogoshi [8] that Ojigi in Japanese daily life is not only a mere practice such as flicking hair everywhere, but it shows noble character which is taught as a manner of courtesy. The procedures to do Ojigi is standing up perfectly as in a line before a person or group of people and then straighten the back. Both feet tighten and both hands aligned on both sides of the body or interlocked in the front. Bow in earnest, without hurry. If you don't know what to say when bowing, say doumo unless when paying the last respects before corpse. In this case, there is no need to say anything. There is also bow to touch the ground, called dogeza. Usually used to apologize extremely or as a highest respect.

\section{Functions and roles of Ojigi}

The function of ojigi in Japanese communication systems is a means to respect the other person, such as respect given tor friends will be different to respect for the superiors. Another function of Ojigi is related to the form of courtesy. In Japan, ojigi serves as a tool to facilitate communication. If ojigi is done well, it will create a good situation among speakers. The role of ojigi in interaction is also very important as a supporter oto support verbal communication, for example when saying thank you or apologizing it will be less if not accompanied by bowing. The role of ojigi is very significant to initiate communication. By doing ojigi, it will facilitate the discharge of verbal communication, and if ojigi is not done then the conversation that occurs will feel unnatural.

In addition, the function of ojigi in a communication system can also be summarized as follows:

1. Ojigi in the Japanese public communication system has a significant position to respect the other person.

2. The type of salutation in ojigi differs depending on the situation and the interlocutor.

3. In a higher level, ojigi is not just respect but it is a form of gratitude, thank you, apologies all of which are part of respect for the other person.

4. Ojigi is a form of Japanese courtesy. 
5. As the time goes by, ojigi does not always mean submitting and obeying the other person, but also the demands of work.

6. Ojigi under certain conditions is able to take the role as verbal communication.

7. In performing ojigi there are two parties involved. In the context of gratitude, a private apology which is he deeper the feeling, the deeper the bow of his head. Conversely, actions shown to the others such as congratulating, Ojigi is not needed.

\section{Sentences spoken in Ojigi}

There are various situations that require someone to do ojigi and say certain the words, such as (1) when meeting, or being aware of the other person precense, and initiating interaction, one will do ojigi while and say greetings (konnichiwa, konbanwa, etc.); (2) when attracting the attention of the speaker and saying sorry at the same time or excusing oneself (sumimasen, anoo, chotto, and so on); (3) shows the intention of separation and saying goodbye or bye at the same moment (sayonara, jaa mata, etc.); (4) showing gratitude and apologies and saying thank you and sorry at the same time (arigatou, doumo, sumimasen, shitsureishimashita, moushiwakenai, and so on); (5) Owing something to the other person (douitashimashite); (6) saying hope to always keep he good relation between each other (yoroshiku onegaishimasu); (7) showing acknowledgement on someone in a conversation (yoroshiku, etc.); (8) expressing gratitude for someone's kindness a few days ago (senjitsu wa doumo, itsuzoya wa arigatou, kono mae wa doumo, and so on); (9) expressing a joy of a meet up (ohissashiburi, ogenki desu ka, etc.).

\section{E. Reasons why Japanese do Ojigi}

There are various reasons why Japanese do ojigi. Based on a study, it is summed up a number of reasons why Japanese people do Ojigi. First, they have gotten use of Ojigi since they were kids. Japanese have known ojigi, since they are in the kindergarten, especially when they arrive and leave the schools. Second, Ojigi is part of the home and school education. Teachers and parents always pay attention and teach them Ojigi in front of the kids as a part of the politeness education. Sometimes, their parents could get angry just because their son do not do ojigi, in a situation where they are supposed to. Third, Ojigi has become a habit that is a must in the surrounding environment. Among students, when meeting with seniors Ojigi is a must. Fourth, it is a dicipline and gratitude. When receiving anything from other people, Ojigi should be done with saying thank you. Fifth, an individu copies Ojigi from his surrounding, especially during a family new year which there are some visits. Sixth, it is done to maintain harmony and to keep the conversation in as part of respecting each other, not insulting.

Besides those seventh reasons, there is one main reason which is according to Kindaichi [12], Japanese are supposed to say little since in some situations they prefer less verbal communications, for example when apologizing instead of say sorry they will just do Ojigi to show their regrets.

\section{F. Implications of Japanese Teaching}

Japanese language education must be integrated with Japanese cultural education. Both lecturers and students need to understand this matter together so that lecturers not only teach linguistics, but also its culture. Similarly, students are more open to the culture of the target language.

The ability to speak Japanese will be even better if it is balanced with the ability of cultural knowledge. As a result, when someone speaks and acts in Japanese language and culture, they do not use their own cultural framework, but instead use the Japanese language and culture framework, so that misunderstandings with speech partners can be avoided.

Even though in Japanese teaching there is a lesson in Nihonjijo (Japanese situation), which tells about the condition and the intricacies of Japan from the viewpoint of society and its nature, and Nihonbunka (related to Japanese culture). However, specifically for nonverbal communication lessons, it seems that it is still less touched. This is indicated by the lack of nonverbal communication lessons in certain subjects in the Japanese Language Department.

\section{CONCLUSION}

Ojigi is a Japanese culture that has become a national identity. The etymological word of ojigi is from the word jigi which means good hope when doing something. Ojigi is interpreted as an expression of respect and removes the conflicts. This custom has been practiced by Japanese since the Yayoi era (10th century BC).

There are two types of ojigi, namely ritsurei and zarei. Ojigi done by standing is called ritsurei, while ojigi done by sitting is called zarei. The procedure for ojigi also varies based on gender.

Common recognized Ojigi are Eshaku, Futsuu no Ojigi, and Teinei na Ojigi. Eshaku in this context actually has a description of bending fifteen degrees and is done when meeting acquaintances or friends. Futsuu no Ojigi, which is a form of bowing the body to the interlocutor at official ceremonies or moments of deep apology. It has thirty degrees angle. Teinei na Ojigi, which is the most polite and most respectful ojigi has forty-five degrees of bend angle or more.

The function of ojigi in Japanese people's communication systems is to respect the other person, such as respect given to friends will be different to respect given to superiors. Another Ojigi function is related to the form of courtesy.

There are various reasons why Japanese do Ojigi. One of which is because they get used to Ojigi since childhood. 


\section{REFERENCES}

[1] Amri, Miftachul, Nihonshakai Ni Okeru Higengo Dentatsu Shudan Toshite No Ojigi, Tesis Tidak diterbitkan. UPI, 2003.

[2] Sugito, Eiju (Aisatsu Kotoba to Miburi) "Kotoba shiri-zu 14 Aisatsu to Kotoba”Bunkacho, 1998.

[3] Kokugo jiten, Shinmeikai Kokugo Jiten Dai 7 Pan. Sanshodou 2012.

[4] Fukuda, Hiroshi. Menjentik, Merayap dan Mendobrak, terjemahan Sugeng. Oriental, 1997.

[5] Daijisen, Oogata.Chuugata Kokugojiten. Shougakukan, 2018.

[6] Shin, Muraide. Kojien, Chuugata no Nihongo Kokugojiten. Iwanamishoten Dai 7 ban. 2018.

[7] Amri, Miftachul, "Study of Ojigi," Bunken kai kiyo-The Journal of Graduate School of Humanities, Nisshin Japan, No. 25, pp. 89-103, 2014.

[8] Ogoshi Mariko. Shigusa no Nichou Taishou Kenkyu Ojigi ni Tsuite. Nihongogaku Meiji shoin. 1995.

[9] Horiuchi, Mineko. Nihongo Hyougen To Bijinesu Manaa, Senmon Kyouiku Shuppan, 1993.

[10] Rahmat, Nandang, "Penelitian Kontrastif Linguistik dan Pendidikan Bahasa Jepang. Sebuah Metode Pemehaman Pemahaman Komunikas Lintas Budaya,” Makalah Seminar Internasional, Surabaya, Agustus 2001.

[11] Nomura, Masaichi, Miburi to shigusa no jinruigaku, Chukoshinsho. 1996.

[12] Kindaichi, Haruhiko. Nihongo no Kokoro, Nihon no Kokoro. Kondansha, 1982 